\title{
Reflexiones sobre el Código Civil italiano y peruano
}

\author{
Francesca Benatti ${ }^{(*)}$ \\ Abogada por la Universidad de Milán. \\ Doctora por la Universidad de Milán. \\ Profesora Asociada de Derecho Privado Comparado de la \\ Universidad de Padua, Italia.
}

(*) Traducción de Carlos Antonio Agurto Gonzáles, profesor de derecho comparado y sistemas jurídicos del mundo de la Universidad Nacional Mayor de San Marcos. Revisado por Benigno Choque Cuenca.

ADVOCATUS agradece a sus Miembros Asociados Diego Antonio Becerra Farje y Jacques Didier D'auriol Augusto por su contribución en la elaboración de las preguntas de la presente entrevista. 


\section{RESUMEN:}

En esta ocasión, ADVOCATUS tuvo la oportunidad de entrevistar a la abogada italiana Francesca Benatti, profesora asociada de Derecho Privado Comparado de la Universidad de Padua. A través de las siguientes líneas se ofrece un breve análisis sobre la vigencia del Código Civil peruano y el Código Civil italiano, abordando elementos del Derecho Civil, incluyendo la responsabilidad civil y el derecho de las personas, así como el derecho comparado.

Palabras clave: Derecho Privado, Código Civil, Italia, Derecho Civil, responsabilidad civil.

\section{ABSTRACT:}

ADVOCATUS had the opportunity to interview Francesca Benatti, Italian lawyer and associate professor of Comparative Private Law at the University of Padua. In the following lines, the interviewee offers a brief analysis on the Peruvian Civil Code and the Italian Civil Code, addressing elements of Civil Law, including torts and Private Law, as well as comparative law.

Keywords: Private Law, Civil Code, Italy, Civil Law, torts.

1. ¿Considera usted que el Código Civil italiano de 1942 -elaborado en el gobierno de Benito Mussolini, en el régimen fascista-, es favorable al mundo económico de nuestro tiempo, en el que se otorga mucha importancia al régimen del libre mercado, como acontece en diversos países del mundo?

No observo una gran dificultad para el Código Civil italiano de 1942 que ha demostrado adaptarse a una realidad económica, social, política diversa y fue lejana de toda conexión con el régimen. La única excepción fue la referencia al ordenamiento corporativo que ha sido eliminada en las normas en que estaba contenida. Hoy se discute mucho de la oportunidad de su reforma para recibir algunas tendencias del derecho europeo, de la praxis internacional o para modernizar algunos ámbitos como el Derecho de Familia y de Sucesiones. Existe también un proyecto de reforma.

No obstante, la recodificación es siempre una operación complicada, como demuestra la reforma francesa que no es plenamente convincente. No me parece ni siquiera tan urgente en Italia: la parte sobre las obligaciones, por ejemplo, permanece perfecta y la del contrato requerirá algunos ajustes, pero en realidad son inútiles, debido a los desarrollos de la jurisprudencia. Es evidente, por ende, que una modificación limitada a solo unos pocos elementos como se desea, podría crear problemas para el sistema. La elec- ción implica reflexiones sobre la teoría general, sobre la función moderna de la codificación y una visión de la sociedad y de su evolución que a menudo falta. Esto fue evidente en los Principles of European Contract Law -Principios de Derecho Europeo de Contratos-PECL- y en el Draft Common Frame of Reference - Proyecto del Marco Común de Referencia-DCFR-. En Europa nos encontramos en una fase de transición y de incerteza que tal vez no permita una serena valoración. Encuentro apreciable la posición expresada por el Conseil fédéral suizo, según el cual:

"(...) el costo de una revisión de la parte general del CO [Código de las Obligaciones] es muy elevado, dado que la utilidad es considerada bastante baja y que el riesgo de cometer errores es considerable. Pero sobre todo son las muy claras opiniones emitidas por los profesionales las que ocupan un lugar central en la apreciación general del Consejo Federal: los especialistas no observan mucha evidencia en el texto normativo, a pesar de las lagunas atestadas, de algún perjuicio mesurable para su trabajo. Por lo tanto, falta una condición esencial para una revisión general" —el agregado es nuestro—.

2. Las nuevas operaciones económicas tienen relación con diversos contratos para obtener un fin económico común. ¿Cómo actúan los remedios contractuales en las operaciones económicas en los contratos coligados o conexos? 
La teoría de los contratos coligados - se trata de aquellos en que las partes estipulan entre ellos negocios diversos, con causas autónomas, pero funcionalmente preordenados a la realización de un diseño unitario- presenta en la práctica numerosos problemas. En primer lugar, si no está explícitamente expresado por cláusulas contractuales, a menudo ocasiona dificultades de interpretación de los contratos que se asumen coligados y esto es un tema delicado - considérese el supuesto en que en uno de los negocios coligados se presente un sujeto que no es parte del otro-, debido a que es una tesis compartida que - donde se encuentre la conexión - la suerte de uno depende de la acontezca con el otro.

La jurisprudencia es del parecer que - cuando los efectos de uno de los contratos no se pueden producir, porque ha sido comprobada la invalidez o ha sido pronunciada la resolución por incumplimiento, por imposibilidad sobrevenida o por excesiva onerosidad, etc.- - están fallando porque el objetivo final deseado por los contratantes, que es la búsqueda de una operación unitaria, se frustra.

En Francia, con la reforma, ha sido introducido el instituto de la caducité - caducidad, artículo 1187-, el cual prevé que el contrato devient caduc - deviene caduco - cuando falta un elemento esencial o, en el caso de la ejecución de una pluralidad de contratos, es necesaria para una misma operación económica y uno de estos disparait —-desaparece-,

"Son contratos nulos cuya ejecución se hace imposible por esta desaparición y aquellos para los cuales la ejecución del contrato desaparecido fue una condición determinante del consentimiento de una parte".

Se consagra una figura ya introducida por la jurisprudencia, pero no parece suficiente para superar todas las incertezas derivadas de su aplicación. Es evidente que la caducité met fin au contrat - la caducidad pone fin al contrato, artículo 1187-, es regulada en modo claro los efectos. Se puede considerar que, como la jurisprudencia constante, no desvirtúa la cláusula compromisoria, la atribución de jurisdicción y de previsión de la cláusula penal, como también la obligación de garantizar al cedente de los créditos la caducidad del bordereau, derivado de la desaparición de la deuda. Complejo es sobre todo el tema de la retroactividad que es dejado a la decisión del juez caso por caso, con notable incerteza e imprevisibilidad de las decisiones.

3. En algunos países, como en el Perú, se han presentado diversos casos de delitos relacionados con la corrupción respecto a la contratación pública. ¿Cuál sería la función de los remedios contractual nulidad-en estos casos?

El problema ha recibido la atención de la doctrina y de la jurisprudencia, especialmente en los años 90 y han sido numerosas sentencias sobre la materia.

La discusión se concentra en la identificación del vicio que afecta el contrato y, por ello, del remedio a ser adoptado.

La opinión casi unánime considera que se está en presencia de una nulidad. Se discute si la nulidad es por violación de las buenas costumbres o del orden público. La solución es importante, porque - si se funda la nulidad en las buenas costumbres - existe la solutio retentio, de acuerdo al artículo 2035, lo que favorecería al corrupto y al corruptor.

La sentencia, para superar esta discusión y evitar el recurso al artículo 2035 del Código Civil,

1. Del francés: "(...) le coût d'une révision de la partie générale du CO [Code des obligations] est très élevé tandis que son utilité est jugée plutôt faible et que le risque d'échec est considérable. Mais c'est surtout les avis très clairs émis par les praticiens qui occupent une place centrale dans l'appréciation générale du Conseil fédéral: les spécialistes ne voient de toute évidence dans le texte normatif, malgré ses lacunes attestées, aucun préjudice mesurable pour leur travail. II manque donc une condition essentielle d'une grande révision" - el agregado es nuestro-. 
construye la nulidad por violación del orden público y de las buenas costumbres, sin distinción. Se trata de una solución que no profundiza el problema, pero desea solo evitar la consecuencia indicada y hoy se puede justificar porque el orden público y las buenas costumbres, según el derecho aplicado, tienen muchos campos en común con la prevalencia de la idea que se amplía la noción de orden público y se restringe siempre más que el de las buenas costumbres, por medio del hecho que no se evidencia más en la sociedad una división de valores éticos.

4. ¿Cuál es el tratamiento normativo en caso de incumplimiento de los deberes de protección en el ordenamiento jurídico italiano?

Los deberes de protección han ingresado en Italia en el lenguaje común de la doctrina y de la jurisprudencia y son considerados una categoría dogmática.

Deben distinguirse las obligaciones instrumentales que son auxiliares de la obligación y su violación se encuentra dentro del supuesto de incumplimiento de la obligación.

Los deberes de protección son deberes autónomos, pero relacionados con la relación obligatoria, y se considera ampliamente que su violación da lugar a dos remedios: compensación por daños o rescisión del contrato, de acuerdo a lo establecido por el artículo 1455 del Código Civil italiano.

La razón radica en el hecho de que se consideran obligaciones técnicas $y$, por lo tanto, se someten al mismo tratamiento que el incumplimiento del servicio cubierto por la obligación.

5. En el proyecto de reforma del Código Civil peruano de 1984 se ha establecido que para la determinación de la responsabilidad civil de los daños producida por el incumplimiento de las obligaciones en el derecho peruano no es necesario la prueba de ningún criterio de imputación subjetiva, debido a la garantía de ejecu- ción de la obligación que tiene el deudor, siendo una responsabilidad de carácter objetiva, respondiendo a los daños solamente por incumplimiento de la obligación. ¿Cuál sería su opinión sobre esta propuesta?

La adopción del criterio de la responsabilidad objetiva es una elección que depende de razones de política judicial.

Es claro que la orientación que se está afirmando es la de la tutela del consumidor. La regla merece consideración, dependerá de cómo será afrontada por la jurisprudencia. Si se trata de simple incumplimiento de una obligación, para evitar controversias, sería oportuno predisponer también una norma que establece la exoneración de responsabilidad del productor en los casos en que sea considerada excesiva.

Debe ser resaltado que la responsabilidad del productor puede encuadrarse en el supuesto de hecho de la venta, del alquiler y de otros contratos, y en este caso valen las reglas de garantía.

6. En el año 2018 se ha producido una reforma del Código Civil peruano, mediante el Decreto Legislativo 1384, que ha reconocido la capacidad jurídica de las personas con (dis)capacidad, considerando que tienen igualdad, con capacidad plena. ¿Cuál es el rol y protección de las personas con (dis)capacidad o de los sujetos débiles en el Código Civil italiano de 1942?

El Código Civil de 1942 preveía para la tutela de las personas en todo, o en parte, privadas de autonomía, las siguientes instituciones:

a) de la minoría de edad;

b) de la interdicción judicial, cuyos presupuestos son: la habitual enfermedad del sujeto; la incapacidad de proveer sus intereses y la necesidad del instrumento;

c) de la inhabilitación respecto a los enfermos mentales menos graves mediante la inter- 
dicción; prodigalidad; abuso de sustancias alcohólicas o estupefacientes, sordidez o ceguera si el sujeto no está en capacidad de atender sus asuntos;

d) de la emancipación y,

e) de la incapacidad de entender y de querer.

En particular en la hipótesis de interdicción, el interdicto se confía a un tutor y está privado de la capacidad de realizar actos jurídicos. La inhabilitación se aplica en los casos menos graves y limita únicamente la capacidad de cumplir los actos de extraordinaria administración.

Se trataba de un sistema rígido que ha encontrado una corrección con la introducción de la administración de apoyo de 2004. El instituto, que ha encontrado grandes éxitos en la práctica y es eficaz, garantiza una protección también a personas que no se encuentran en las condiciones establecidas por la interdicción y la inhabilitación. Es una previsión limitada y configurada en base de las concretas y específicas exigencias, a veces solo temporales, del sujeto. 